Article

\title{
Control Performances of Friction Pendulum and Sloped Rolling-Type Bearings Designed with Single Parameters
}

\author{
Shiang-Jung Wang ${ }^{1, * \mathbb{C}}$, Yi-Lin Sung ${ }^{1}$, Cho-Yen Yang ${ }^{2}$, Wang-Chuen Lin ${ }^{2}$ and Chung-Han Yu ${ }^{2} \mathbb{C}$ \\ 1 Department of Civil and Construction Engineering, National Taiwan University of Science and Technology, \\ Taipei 106335, Taiwan; m10705323@mail.ntust.edu.tw \\ 2 National Center for Research on Earthquake Engineering, Taipei 106219, Taiwan; \\ choyen@narlabs.org.tw (C.-Y.Y.); wclin@narlabs.org.tw (W.-C.L.); chyu@narlabs.org.tw (C.-H.Y.) \\ * Correspondence: sjwang@mail.ntust.edu.tw; Tel.: +886-2-27303650
}

Received: 9 September 2020; Accepted: 13 October 2020; Published: 15 October 2020

\begin{abstract}
Owing to quite different features and hysteretic behavior of friction pendulum bearings (FPBs) and sloped rolling-type bearings (SRBs), their control performances might not be readily compared without some rules. In this study, first, on the premise of retaining the same horizontal acceleration control performance, the effects arising from different sloping angles and damping forces on the horizontal maximum and residual displacement responses of SRBs are numerically examined. For objective comparison of passive control performances of FPBs and SRBs, then, some criteria are considered to design FPBs with the same horizontal acceleration control performance by referring to the designed damping force and the maximum horizontal displacement response of SRBs under a given seismic demand. Based on the considered criteria, the passive control performances of FPBs and SRBs under a large number of far-field and pulse-like near-fault ground motions are quantitatively compared. The numerical comparison results indicate that the FPB models might potentially have better horizontal acceleration and isolation displacement control performances than the SRB models regardless of whether they are subjected to far-field or near-fault ground motions, while the opposite tendency is observed for their self-centering performances, especially when the SRB model designed with a larger sloping angle or a smaller damping force.
\end{abstract}

Keywords: friction pendulum bearing; sloped rolling-type bearing; numerical comparison; control performance; self-centering

\section{Introduction}

\subsection{Literature Review}

On a theoretical basis, the satisfactory seismic performances of friction pendulum bearings (FPBs) and sloped rolling-type bearings (SRBs) have been demonstrated separately in many past numerical and experimental studies [1,2]. Well-developed analytical models, including simplified and sophisticated ones, have also been proposed and verified to be capable of predicting the dynamic behavior of FPBs and SRBs, accordingly. Currently, FPBs and SRBs, the former in particular, have been widely applied in engineering practice for seismically protecting critical structures, facilities, and equipment to guarantee their desired functionality during and after earthquakes.

FPBs designed with a single curvature radius and friction coefficient [3-6], as illustrated in Figure $1 \mathrm{a}$, undoubtedly, possess a very simple and reliable mechanism together with idealized bilinear hysteretic behavior, as shown in Figure 2. The details about the unique features of FPBs and the notations presented in the figures will be further explained in Section 1.2. In the past few decades, 
in addition to adjusting the design parameters of FPBs for better estimating and enhancing their control performances [7], there have also been many studies on mechanically modifying and upgrading FPBs to offer designers greater flexibility to optimize their performance as much as possible at different design stages. The FPBs, which can individually or simultaneously present variable energy dissipation and different stiffness (or restoring force) capabilities by correspondingly designing different friction coefficients and varying curvature radii, such as the so-called double, triple, and even quintuple FPBs, were analytically and experimentally studied by Fenz and Constantinou [8,9], Kim YS and Yu CB [10], Calvi et al. [11], Panchal and Jangid [12], Bao and Becker [13], and Lee and Constantinou [14]. Besides concave sliding surface designs, Lu et al. [15] and Saha et al. [16] analytically and experimentally studied some complicated polynomial functions designed for the sliding surfaces of FPBs so as to present variable stiffness properties and thus achieve multiple design objectives. Furthermore, in addition to studying the unilateral behavior of double or triple FPBs, their multi-axial behavior was thoroughly studied by Panchal et al. [17], Becker and Mahin [18], Sah and Soni [19], and Furinghetti et al. [20]. Some research results indicated that the effect arising from vertical excitations on the horizontal seismic performance of double or triple FPBs might not be negligible for obtaining more accurate and conservative design results [21,22]. Recently, not only far-field ground motions but the so-called pulse-like near-fault ones were also considered in many relevant studies to propose the corresponding design strategies for FPBs [12,23]. The post-earthquake self-centering capability of double or triple FPBs, which is another important performance index for seismic isolation and will significantly affect serviceability and functionality of isolated superstructures and nonstructural components (or systems) crossing isolation layers after earthquakes, was also theoretically and experimentally studied by Katsaras et al. [24], Cardone et al. [25], and Ponzo et al. [26]. Besides applying FPBs to new construction, their applicability and economic performance for seismically retrofitting existing structures, with consideration to soil deformability, have also been studied [27].

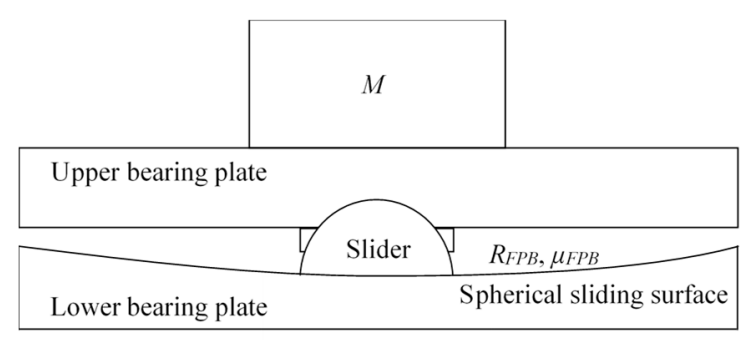

(a) FPB.

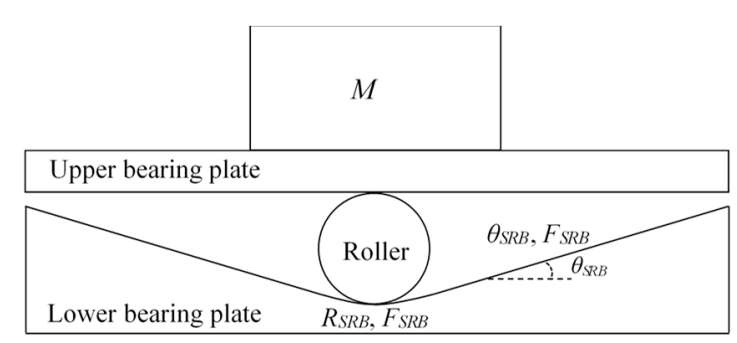

(b) SRB.

Figure 1. Simplified models for friction pendulum bearings (FPBs) and sloped rolling-type bearings (SRBs).

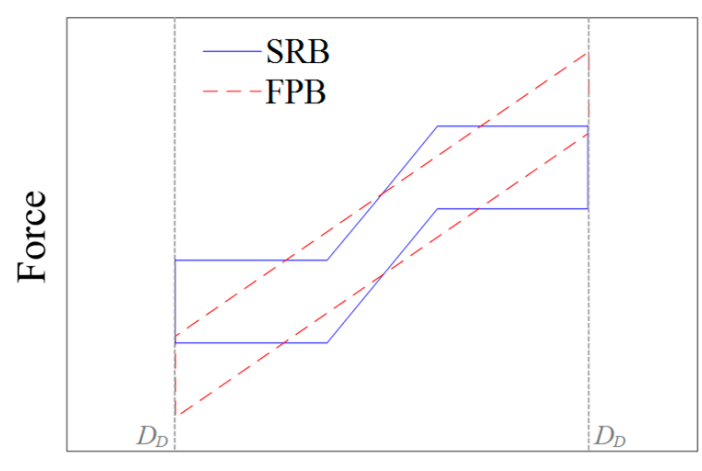

Displacement

Figure 2. Typical hysteretic behavior of FPBs and SRBs. 
SRBs designed with a constant sloping angle and damping force [28-33], as illustrated in Figure 1b, mechanically exhibit the so-called twin-flag hysteretic behavior as also shown in Figure 2. The details about the unique features of SRBs and the notations presented in the figures will be further explained in Section 1.2. In the past decade, there have been some studies on mechanically modifying and upgrading SRBs to offer designers greater flexibility to optimize their performance as much as possible at different design stages. Without limiting the horizontal acceleration control performance, Wang et al. [34] numerically investigated the influences of different combinations of sloping angles and damping forces on the horizontal displacement control performance of SRBs, and accordingly, proposed some empirical formulas for practically and conservatively approximating the maximum horizontal displacement of SRBs under a given seismic demand characterized by the effective peak acceleration and corner period. In addition to SRBs designed with constant parameters, those designed with linearly variable damping forces, as well as those designed with stepwise variable sloping angles and damping forces, were analytically and experimentally studied to meet diverse control performance goals [35]. The post-earthquake self-centering capability of SRBs (or more generalized forms, the isolation bearings possessing flag-shaped hysteretic behavior) was theoretically, numerically, and experimentally studied [35,36].

\subsection{Formulas and Considerations}

The simplified and linearized equation of motion of FPBs for a single-degree-of-freedom (SDOF) system shown in Figure 1a is given in Equation (1) [3-6].

$$
F=-M\left(\ddot{u}+\ddot{u}_{g}\right)=\frac{M g}{R_{F P B}} u+F_{F P B} \operatorname{sgn}(\dot{u}),
$$

where $F$ is the inertia force; $M$ is the mass of the protected object above the isolation bearing; $g$ is the acceleration of gravity; $R_{F P B}$ is the curvature radius of the spherical sliding surface; $F_{F P B}$ is the friction damping force, which is usually approximated by the product of $M g$ and the friction coefficient $\mu_{F P B}$ between two mutual-contact sliding surfaces; $u, \dot{u}$, and $\ddot{u}$ are the displacement, velocity, and acceleration of the upper bearing plate (or the protected object) relative to the lower bearing plate (the ground usually), respectively; $\ddot{u}_{g}$ is the horizontal acceleration excitation.

As observed from Figure 2 and Equation (1), once the design displacement $D_{D}, R_{F P B}$, and $F_{F P B}$ are determined, the effective horizontal stiffness $K_{\text {eff }}$ and the effective horizontal period $T_{\text {eff }}$ at $D_{D}$ can be mathematically calculated by Equations (2) and (3), respectively [3-6].

$$
\begin{gathered}
K_{\text {eff }}=\frac{M g}{R_{F P B}}+\frac{F_{F P B}}{D_{D}}=\left(\frac{1}{R_{F P B}}+\frac{\mu_{F P B}}{D_{D}}\right) M g, \\
T_{e f f}=2 \pi \sqrt{\frac{M g}{\left(\frac{M g}{R_{F P B}}+\frac{F_{F P B}}{D_{D}}\right) g}}=2 \pi \sqrt{\frac{1}{\left(\frac{1}{R_{F P B}}+\frac{\mu_{F P B}}{D_{D}}\right) g} .}
\end{gathered}
$$

The unique features of FPBs can be directly observed from Equations (2) and (3) [3-6]. The effective horizontal stiffness is proportional to the mass of the protected object above, thus easily overcoming the inherent and accidental eccentricity problems, especially when the protected object is a highly irregular architectural design. In addition, the effective horizontal period is independent of the mass of the protected object above. In other words, the effective horizontal period, which is the most important design parameter when performing the linear static or dynamic analysis [37], will not be affected if the mass of the protected object after construction varies in use or is different from the initial assumed mass.

The simplified and linearized equations of motion of SRBs at the slope and arc rolling stages for the SDOF system shown in Figure $1 \mathrm{~b}$ are given in Equations (4) and (5), respectively [32-34].

$$
F=-M\left(\ddot{u}+\ddot{u}_{g}\right)=\frac{M g \theta_{S R B}}{2} \operatorname{sgn}(u)+F_{S R B} \operatorname{sgn}(\dot{u}),
$$




$$
F=-M\left(\ddot{u}+\ddot{u}_{g}\right)=\frac{M g}{4 R_{S R B}} u+F_{S R B} \operatorname{sgn}(\dot{u}),
$$

where $\theta_{S R B}$ is the sloping angle of the sloped rolling surface; $F_{S R B}$ is the friction damping force; $R_{S R B}$ is the curvature radius of the arc rolling surface.

The unique feature of SRBs can be directly observed from Equation (4) and Figure 2 [29-33]. With a fixed sloping angle and damping force, the horizontal acceleration transmitted to the protected object above can remain constant regardless of any intensity and frequency content of external disturbance. Accordingly, SRBs do not have a fixed natural period and can offer maximum horizontal decoupling between the protected object and external disturbance.

\subsection{Objectives of This Study}

In view of quite different features and hysteretic behavior revealed by FPBs and SRBs, their passive control performances might not be readily and objectively compared without some rules. In this study, first, some criteria are considered to objectively design FPBs with the same horizontal acceleration control performance by referring to the designed damping force and the maximum horizontal displacement response of SRBs under a given seismic demand. Then, based on the considered criteria, the passive control performances of FPBs are numerically and quantitatively compared with those of SRBs, in terms of horizontal acceleration, isolation displacement, and residual displacement, under a large number of far-field and pulse-like near-fault ground motions. It is emphasized that with a given constant horizontal acceleration control performance, numerically comparing seismic responses of FPBs with those of SRBs based on an objective design criterion, rather than seeking optimum design parameters separately for FPBs and SRBs, is the main purpose of this study.

\section{Ground Motions Considered}

Three groups of horizontal ground motions recorded at ground surfaces with different site conditions (or soil effects) during past local and global earthquakes were adopted as horizontal acceleration inputs in this study. More precisely, the ground motion histories were mathematically substituted into $\ddot{u}_{g}$ in Equations (1), (4) and (5). The first group (denoted as Group 1 hereafter) contained 2553 sets of local ground motion records with peak ground acceleration (PGA) values varying from $0.082 \mathrm{~g}$ to $1.260 \mathrm{~g}$ and peak ground velocity (PGV) varying from $0.006 \mathrm{~m} / \mathrm{s}^{2}$ to $2.800 \mathrm{~m} / \mathrm{s}^{2}$, which were collected by the Taiwan Strong Motion Instrument Program (TSMIP) during 29 July 1992 to 31 December 2006. Among these, 16 sets of records were classified as pulse-like near-fault ground motions [38], and the remaining were classified as far-field ground motions. The second and third groups (hereafter denoted as Group 2 and Group 3, respectively) correspondingly contained 25 sets of far-field ground motion records and 41 sets of pulse-like near-fault ground motion records [38] during past global earthquakes, which were collected by the Pacific Earthquake Engineering Research Center (PEER). The PGA and PGV values of ground motion records of Group 2 varied from $0.152 \mathrm{~g}$ to $0.621 \mathrm{~g}$ and from $0.208 \mathrm{~m} / \mathrm{s}^{2}$ to $0.704 \mathrm{~m} / \mathrm{s}^{2}$, respectively, and the PGA and PGV values of ground motion records of Group 3 varied from $0.144 \mathrm{~g}$ to $1.129 \mathrm{~g}$ and from $0.440 \mathrm{~m} / \mathrm{s}^{2}$ to $1.479 \mathrm{~m} / \mathrm{s}^{2}$, respectively. The basic information of these ground motions, including the earthquake, year of occurrence, station name (as the denotation hereafter), PGA, and PGV, is summarized in Table 1. Note that adopting Group 1 aims to more clearly identify the influences of different design parameters on wide-ranging seismic responses of SRBs, while adopting Groups 2 and 3, can further discuss and understand the individual potential merits of FPBs and SRBs subjected to far-field and pulse-like near-fault ground motions. Thus, it can be seen that a few ground motions classified into Groups 2 and 3 were duplicated in Group 1. 
Table 1. Ground motions considered for horizontal acceleration inputs ( ${ }^{*}$ denotes the ground motions duplicated in Groups 1 and 2 (or 3$)$ ).

\begin{tabular}{|c|c|c|c|c|c|c|c|c|c|c|}
\hline & Earthquake & Year & Station Name & PGA $(g)$ & PGV (m/s) & Earthquake & Year & Station Name & PGA $(g)$ & PGV (m/s) \\
\hline Group 1 & - & 1992-2006 & - & $0.082-1.260$ & $0.006-2.800$ & & & & & \\
\hline \multirow{13}{*}{ Group 2} & El Centro & 1940 & American Imperial Valley & 0.281 & 0.309 & \multirow{5}{*}{ Japan Kobe } & \multirow{5}{*}{1995} & Kakogwa (000) & 0.240 & 0.208 \\
\hline & $\begin{array}{l}\text { American Imperial } \\
\text { Valley }\end{array}$ & 1979 & Delta (352) & 0.350 & 0.330 & & & Shin-Osaka (090) & 0.233 & 0.218 \\
\hline & $\begin{array}{c}\text { American } \\
\text { Superstition Hills }\end{array}$ & 1987 & Poe Road (270) & 0.475 & 0.412 & & & MRG (000) & 0.214 & 0.270 \\
\hline & \multirow{2}{*}{$\begin{array}{l}\text { American Loma } \\
\text { Prieta }\end{array}$} & \multirow{2}{*}{1989} & Gilroy Array \#3 (000) & 0.559 & 0.363 & & & Fukushima (000) & 0.185 & 0.314 \\
\hline & & & Capitola (090) & 0.439 & 0.296 & & & Yae $(000)$ & 0.158 & 0.212 \\
\hline & Iran Manjil & 1990 & Abbar (L) & 0.515 & 0.425 & Turkey Kocaeli & 1999 & Duzce (270) & 0.364 & 0.557 \\
\hline & American Landers & 1992 & Yermo Fire (360) & 0.152 & 0.291 & \multirow{6}{*}{ Taiwan Chi-Chi } & \multirow{6}{*}{1999} & TCU074 (EW)* & 0.597 & 0.704 \\
\hline & \multirow{4}{*}{$\begin{array}{l}\text { American } \\
\text { Northridge }\end{array}$} & \multirow{4}{*}{1994} & Beverly Hills-12520 Mulhol (035) & 0.621 & 0.288 & & & TCU045 (NS) & 0.522 & 0.460 \\
\hline & & & Canyon Country (270) & 0.472 & 0.411 & & & TCU088 $(\mathrm{EW}) *$ & 0.519 & 0.137 \\
\hline & & & LA-Saturn St (020) & 0.468 & 0.372 & & & TCU047 (NS) & 0.407 & 0.333 \\
\hline & & & LA-Hollywood Stor FF (360) & 0.358 & 0.274 & & & NST (NS) & 0.399 & 0.329 \\
\hline & \multirow{2}{*}{ Japan Kobe } & \multirow{2}{*}{1995} & Nishi-Akashi (000) & 0.483 & 0.468 & & & TCU089 $(\mathrm{EW}) *$ & 0.355 & 0.508 \\
\hline & & & Tadoka (000) & 0.296 & 0.245 & & & & & \\
\hline \multirow[b]{5}{*}{ Group 3} & $\begin{array}{l}\text { American San } \\
\text { Fernanado }\end{array}$ & 1971 & Pacoima Dam (upper left abut) (164) & 1.129 & 1.144 & Taiwan Chi-Chi & 1999 & TCU128 $(\mathrm{EW})^{*}$ & 0.144 & 0.642 \\
\hline & $\begin{array}{c}\text { American } \\
\text { Superstition }\end{array}$ & 1987 & Parachute Test Site (225) & 0.429 & 1.342 & \multirow[b]{2}{*}{ Turkey Kocaeli } & \multirow[b]{2}{*}{1999} & Yarimca (150) & 0.320 & 0.719 \\
\hline & $\begin{array}{c}\text { American } \\
\text { Lexington Dam }\end{array}$ & 1989 & LosGatos (090) & 0.409 & 0.957 & & & Yarimca (060) & 0.226 & 0.697 \\
\hline & $\begin{array}{l}\text { American Cape } \\
\text { Mendocino }\end{array}$ & 1992 & Petrolia (090) & 0.605 & 0.885 & $\begin{array}{l}\text { New Zealand } \\
\text { Darfield }\end{array}$ & 2010 & HORC (S72E) & 0.472 & 0.698 \\
\hline & Turkey Erzincan & 1992 & Erzincan (NS) & 0.385 & 1.071 & $\begin{array}{c}\text { Taiwan } \\
\text { Meinong }\end{array}$ & 2016 & CHY089 (NS) & 0.288 & 0.577 \\
\hline
\end{tabular}


Table 1. Cont.

\begin{tabular}{|c|c|c|c|c|c|c|c|c|c|}
\hline Earthquake & Year & Station Name & PGA $(g)$ & PGV (m/s) & Earthquake & Year & Station Name & PGA $(g)$ & PGV (m/s) \\
\hline \multirow{6}{*}{$\begin{array}{l}\text { American } \\
\text { Northridge }\end{array}$} & \multirow{6}{*}{1994} & Pacoima Dam (upper left) (194) & 0.989 & 1.033 & \multirow{16}{*}{ Taiwan Hualien } & \multirow{16}{*}{2018} & HWA019 (EW) * & 0.411 & 1.384 \\
\hline & & Rinaldi (228) & 0.869 & 1.479 & & & HWA008 (NS) & 0.343 & 0.861 \\
\hline & & Sylmar-Converter Sta East (011) & 0.851 & 1.209 & & & MND016 (EW) * & 0.306 & 1.336 \\
\hline & & Sylmar-Olive View Med FF (360) & 0.798 & 1.293 & & & HWA007 (EW) * & 0.295 & 1.034 \\
\hline & & Sylmar-Converter Sta (052) & 0.617 & 1.162 & & & HWA012 (EW) * & 0.285 & 0.866 \\
\hline & & $\begin{array}{c}\text { Jensen Filter Plant Generator } \\
\text { Building (022) }\end{array}$ & 0.569 & 0.761 & & & HWA063 (NS) & 0.258 & 0.997 \\
\hline \multirow{10}{*}{ Taiwan Chi-Chi } & \multirow{10}{*}{1999} & TCU067 (EW)* & 0.498 & 0.983 & & & HWA028 (NS) & 0.258 & 0.517 \\
\hline & & CHY101 (NS) & 0.398 & 1.073 & & & HWA009 (EW) * & 0.255 & 1.104 \\
\hline & & TCU052 (EW)* & 0.357 & 1.746 & & & HWA008 (EW) * & 0.235 & 0.992 \\
\hline & & CHY101 (EW)* & 0.340 & 0.672 & & & HWA $062(\mathrm{EW})^{*}$ & 0.213 & 0.956 \\
\hline & & TCU075 (EW) * & 0.330 & 1.161 & & & TRB042 (EW)* & 0.208 & 0.656 \\
\hline & & TCU102 $(\mathrm{EW}) *$ & 0.310 & 0.874 & & & HWA062 (NS) & 0.207 & 0.764 \\
\hline & & CHY024 (EW) * & 0.282 & 0.529 & & & HWA011 (NS) & 0.203 & 0.871 \\
\hline & & TCU063 (EW) * & 0.183 & 0.440 & & & HWA050 (NS) & 0.202 & 0.763 \\
\hline & & TCU102 (NS) & 0.172 & 0.713 & & & TRB042 (NS) & 0.190 & 0.826 \\
\hline & & TCU128 (NS) & 0.166 & 0.626 & & & & & \\
\hline
\end{tabular}




\section{Effects of Different Design Parameters on the Displacement of SRBs with Identical Acceleration Control Performance}

\subsection{Analytical Model for SRBS}

The simplified analytical model for characterizing the horizontal dynamic behavior of SRBs adopted in this study, conceptually and practically, can be decomposed into two parts, a multilinear elastic model and a rigid-perfectly plastic model to correspondingly represent the backbone and energy dissipation of SRBs, as illustrated in Figure 3, from which the physical meanings of Equations (4) and (5) can be understood more clearly. For simplicity and essential comparison without other more complicated factors, the influences arising from different velocities, axial pressures, temperatures, and breakaway frictions on the friction damping behavior of SRBs [5,39] were neglected. In addition, the external disturbance and dynamic responses in only one horizontal principle direction were considered herein.

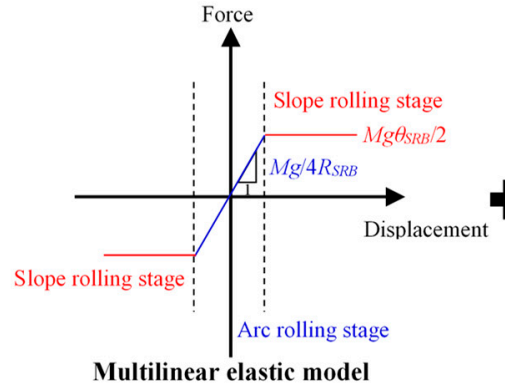

Multilinear elastic model

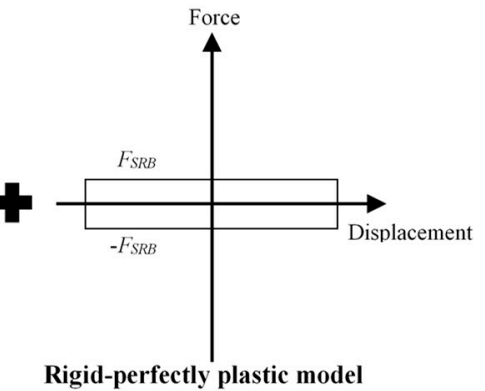

Rigid-perfectly plastic model

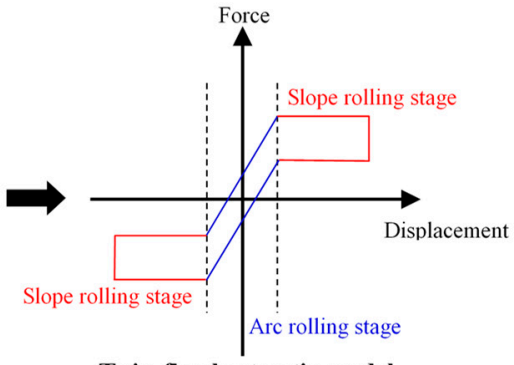

Twin-flag hysteretic model

Figure 3. Idealized composition of analytical models for SRBs.

\subsection{SRB Models}

As summarized in Table 2, four SRB models were designed with sloping angles of 3, 4, 6, and 8 degrees, hereafter denoted as SRB-3, SRB-4, SRB-6, and SRB-8, respectively. To keep an approximately constant horizontal acceleration response of $0.08 \mathrm{~g}$ for these four models at the slope rolling stage, which is different from the comparison basis of Wang et al.'s previous study [34], the friction damping forces were accordingly designed as 550 N, 460 N, 300 N, and 120 N for SRB-3, SRB-4, SRB-6, and SRB-8, respectively. In addition, to coordinate different sloping angles of 3, 4, 6, and 8 degrees at the slope rolling stage with a fixed curvature radius of $100 \mathrm{~mm}$ at the arc rolling stage, the arc rolling ranges (or horizontal displacement ranges) at this stage for SRB-3, SRB-4, SRB-6, and SRB-8 were designed to be $10.5 \mathrm{~mm}, 14 \mathrm{~mm}, 21 \mathrm{~mm}$, and $28 \mathrm{~mm}$, respectively. The friction damping force designed at the arc rolling stage, certainly, was the same as that at the slope rolling stage. The hysteresis loops of SRB-3, SRB-4, SRB-6, and SRB-8 are illustrated in Figure 4 for better comparison.

Table 2. Design parameters of SRBs and FPBs.

\begin{tabular}{|c|c|c|c|c|c|c|}
\hline \multirow{3}{*}{ Model } & \multicolumn{3}{|c|}{ Arc Rolling Stage } & \multicolumn{3}{|c|}{ Slope Rolling Stage } \\
\hline & \multirow{2}{*}{$\begin{array}{c}\text { Range / Design } \\
\text { Displacement } \\
\left(D_{D}\right)_{i}(\mathrm{~mm})\end{array}$} & \multirow{2}{*}{$\begin{array}{c}\text { Curvature } \\
\text { Radius (mm) }\end{array}$} & \multirow{2}{*}{$\begin{array}{l}\text { Friction } \\
\text { Damping } \\
\text { Force (N) }\end{array}$} & \multicolumn{2}{|c|}{ Sloping Angle $\left({ }^{\circ}\right)$} & \multirow{2}{*}{$\begin{array}{c}\text { Friction } \\
\text { Damping } \\
\text { Force (N) }\end{array}$} \\
\hline & & & & $\begin{array}{l}\text { Upper Bearing } \\
\text { Plate }\end{array}$ & $\begin{array}{c}\text { Lower Bearing } \\
\text { Plate }\end{array}$ & \\
\hline SRB-3 & 10.5 & 100 & 550 & 0 & 3 & 550 \\
\hline SRB-4 & 14 & 100 & 460 & 0 & 4 & 460 \\
\hline SRB-6 & 21 & 100 & 300 & 0 & 6 & 300 \\
\hline SRB-8 & 28 & 100 & 120 & 0 & 8 & 120 \\
\hline FPB-3-2M & 63.78 & 2550 & 550 & - & - & - \\
\hline FPB-3-3M & 494.70 & 19,800 & 550 & - & - & - \\
\hline FPB-6-2M & 90.64 & 1810 & 300 & - & - & - \\
\hline FPB-6-3M & 704.30 & 14,100 & 300 & - & - & - \\
\hline
\end{tabular}




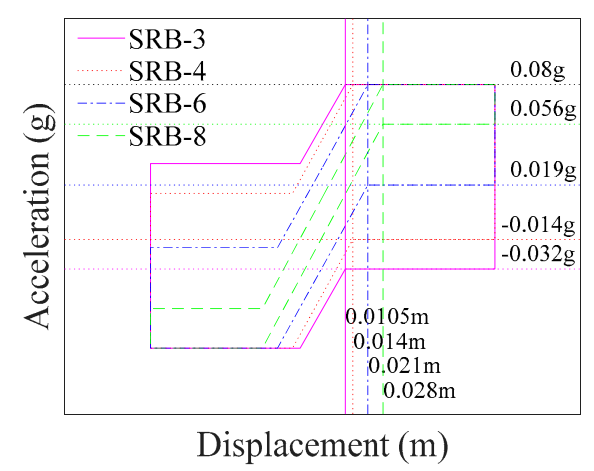

Figure 4. Hysteresis loops of four different SRB models with the same horizontal acceleration control performance.

\subsection{Numerical Simulations and Results}

A to-be-protected object above the SRB models was assumed to be important equipment with a mass of $1000 \mathrm{~kg}$ located on the first floor of a building structure, e.g., a storage system for wafers used in high-tech industries. For simplicity, the SDOF assumption still held in the numerical simulation, i.e., the isolation mode predominated the overall dynamic behavior of the isolated equipment. At each time step of ground motions of Groups 1, 2, and 3, the Newmark- $\beta$ method with linear acceleration was used for solving Equations (4) and (5) correspondingly when at the slope and arc rolling stages. During two or more consecutive time steps in numerical integration, there could be no relative motion between the upper and lower bearing plates, as shown in Figure 1b. Therefore, the sticking phase [40], which will significantly affect the post-earthquake re-centering performance, was taken into consideration. By setting $\ddot{u}$ in Equations (4) and (5) equal to zero, the critical characteristic strengths at the slope and arc rolling stages, which are the criteria to identify if the slipping or sticking phase occurs [40], could be defined and calculated by Equations (6) and (7), respectively. More precisely, if $F_{S R B}^{C}$ is calculated to be smaller than the designed damping force $F_{S R B}$ at a specific time step (e.g., at $\left.t_{i}\right)$, the sticking phase will occur. In this case, at the time step $t_{i}, \ddot{u}$ and $\dot{u}$ should be set to zero, and $u$ should remain the same as that at the previous time step $t_{i-1}$. Note that $F_{S R B}^{C}$ at the slope rolling stage is only related to $\ddot{u}_{g}$ once $\theta$ is determined, while $F_{S R B}^{C}$ at the arc rolling stage is also related to $u$, in addition to $\ddot{u}_{g}$, once $R_{S R B}$ is determined.

$$
\begin{gathered}
F_{S R B}^{C}=\left|M \ddot{u}_{g}+\frac{M g \theta_{S R B}}{2} \operatorname{sgn}(u)\right|, \\
F_{S R B}^{C}=\left|M \ddot{u}_{g}+\frac{M g}{4 R_{S R B}} u\right| .
\end{gathered}
$$

With sloping angles of 3,4,6, and 8 degrees at the slope rolling stage, the magnitudes of $F_{S R B}^{C}$ after excitations, i.e., $\ddot{u}_{g}=0$, were correspondingly $256.83 \mathrm{~N}, 342.43 \mathrm{~N}, 513.65 \mathrm{~N}$, and $684.87 \mathrm{~N}$, of which the first two and the last two are smaller than and larger than their designed damping forces, respectively. It also means that for the designs with sloping angles of 3 and 4 degrees, if the magnitudes of $\ddot{u}_{g}$ during external disturbance are correspondingly larger than $0.030 \mathrm{~g}$ and $0.012 \mathrm{~g}$ with the same direction as $u$ or larger than $0.082 \mathrm{~g}$ with the opposite direction to $u$, the motion between the superior and inferior bearing plates can still be in the slipping phase.

The horizontal maximum and residual displacement responses of SRB-3, SRB-4, SRB-6, and SRB-8 subjected to ground motions of Groups 1, 2, and 3 are presented in Figures 5-7, respectively. As for the maximum horizontal displacement responses subjected to ground motions of Group 1, another presentation, i.e., the maximum horizontal displacement responses versus PGV in a logarithm scale, is also provided for better observation. The maximum horizontal displacement responses of SRBs have been numerically demonstrated to be almost linearly proportional to PGV on a logarithm scale [41]. 
In these figures, in addition to mean responses, the 25 th and 75 th percentile responses are also provided for further statistical comparison. Since all the SRB models were designed with the same curvature radius at the arc rolling stage, the numerical results at the arc rolling stage (including still at the equilibrium position if there are any) are covered in the figures and the following discussions.
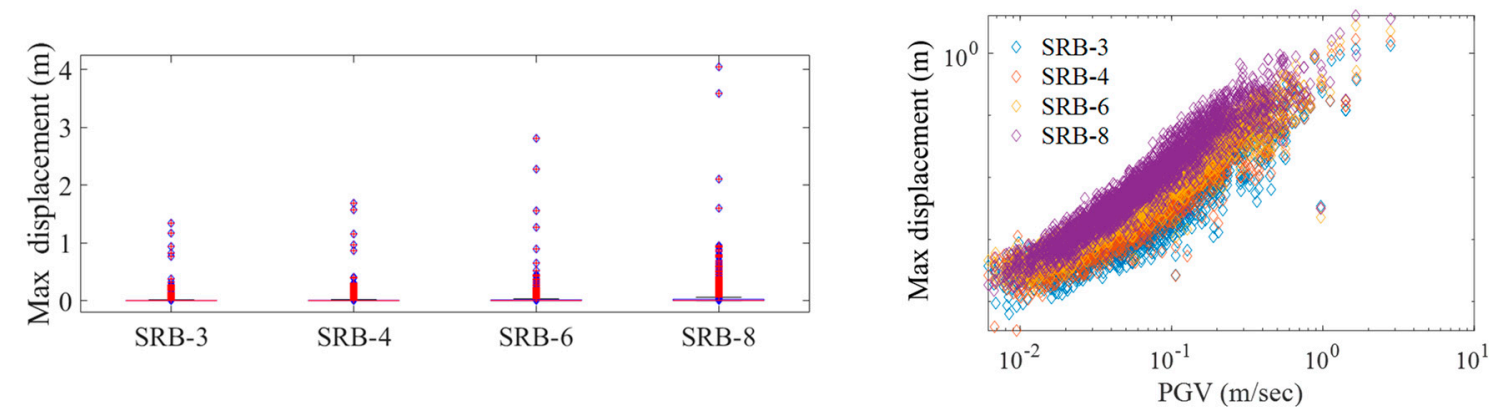

(a) Maximum displacement responses.

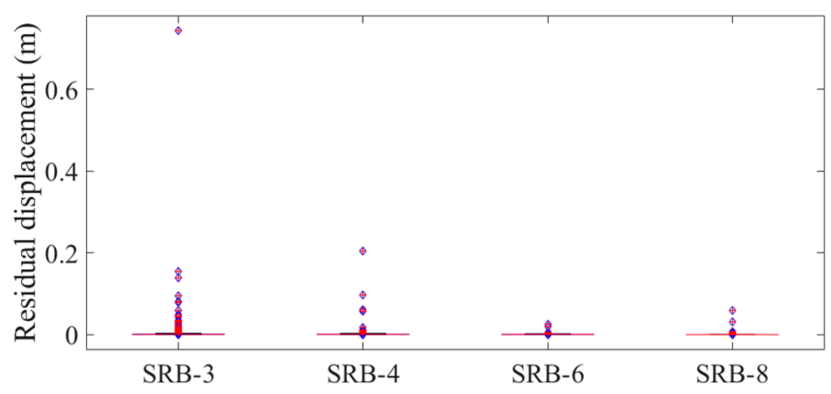

(b) Residual displacement responses.

Figure 5. Comparisons of displacement control performances of different SRB models subjected to ground motions of Group 1.

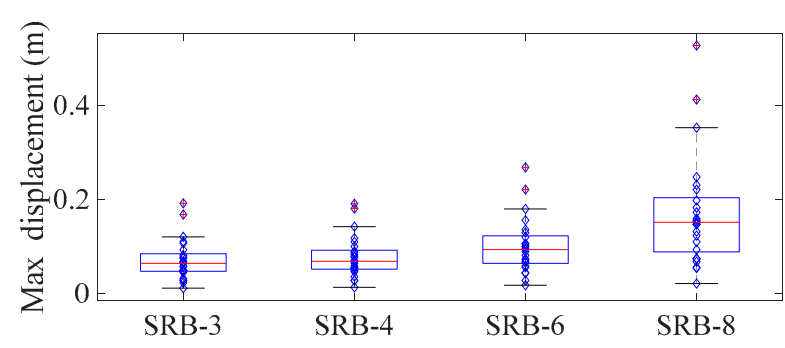

(a) Maximum displacement responses.

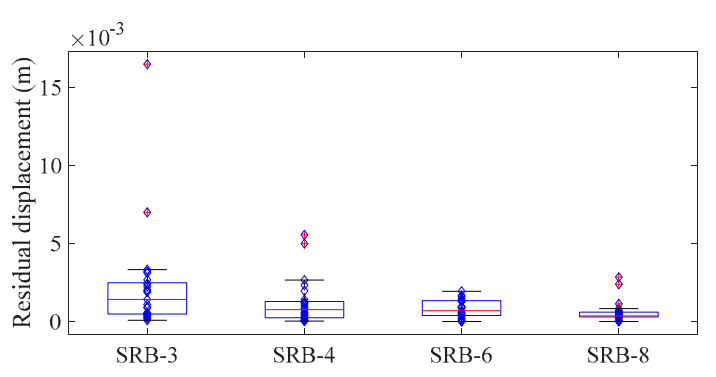

(b) Residual displacement responses.

Figure 6. Comparisons of displacement control performances of different SRB models subjected to ground motions of Group 2.

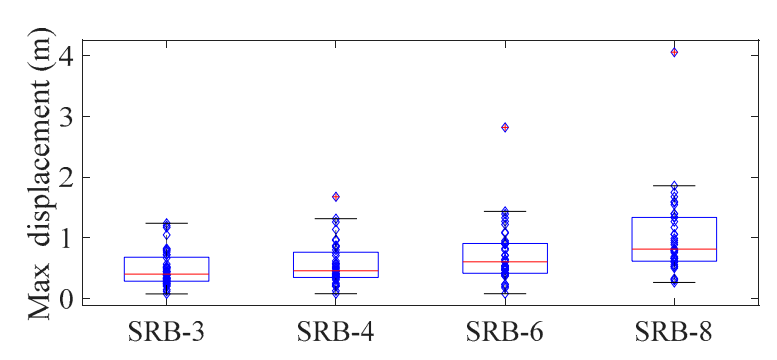

(a) Maximum displacement responses.

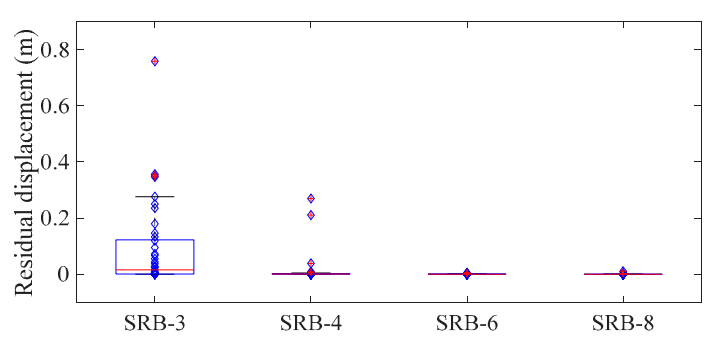

(b) Residual displacement responses.

Figure 7. Comparisons of displacement control performances of different SRB models subjected to ground motions of Group 3. 
As observed from these figures, based on retaining the same horizontal acceleration control performance, adopting a constant sloping angle and damping force for SRBs might not entirely control their horizontal maximum and residual displacement responses simultaneously. On average and in terms of distribution, the increase in damping forces (or energy dissipation capability) or the decrease in sloping angles will lead to a decrease in horizontal isolation displacement but an increase in residual displacement, even though most of the residual displacement responses of all the SRB models subjected to ground motions of Group 2, i.e., far-field ground motions, were very limited (an order of $10^{-4}$ to $10^{-3} \mathrm{~m}$ ) and practically acceptable. The satisfactory self-centering performances revealed by SRB-6 and SRB-8 is no surprise since their calculated values of $F_{S R B}^{C}$ after excitations as per Equation (6) were larger than their designed damping forces. Their higher potential energy compared with SRB-3 and SRB-4 when at the same horizontal displacement response can also be physically understood. Taking SRB-8, under the 1987 American Superstition, Parachute Test Site (225) as an example for an insight into the details, as shown in Figure 8, the displacement response at the end of the ground motion and the final residual displacement response after free vibration were $573.20 \mathrm{~mm}$ and 0.54 mm, respectively. For SRB-3 and SRB-4, in some cases, when the magnitudes of $\ddot{u}_{g}$ at the end of ground motions were sufficiently large to overcome their designed damping forces, their self-centering performances were still acceptable but not as good as the performances of SRB-6 and SRB-8. In brief, an excessive damping force for SRBs will cause the sticking phase occurring more frequently during motion and thus generally has an adverse effect on the self-centering capability of SRBs.
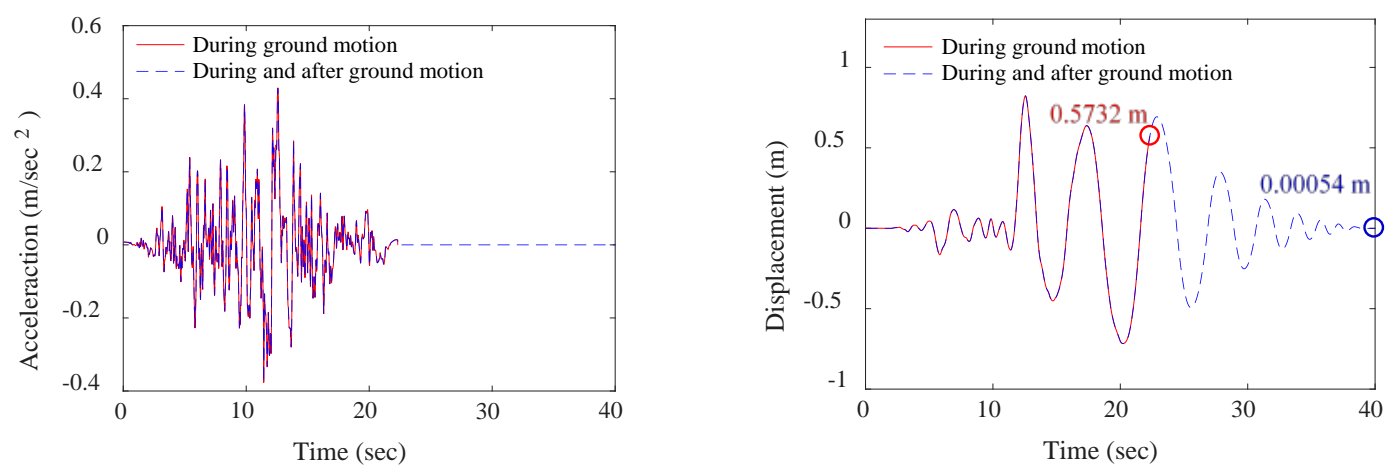

Figure 8. Displacement response histories and residual displacement of SRB-8 under the 1987 American Superstition, Parachute Test Site (225).

\section{Numerical Comparisons between FPBs and SRBs}

\subsection{Analytical Model for FPBs}

The simplified analytical model for describing the horizontal dynamic behavior of FPBs adopted in this study, conceptually and practically, can be decomposed into two parts, a linear elastic model and a rigid-perfectly plastic model to correspondingly represent the backbone and energy dissipation of FPBs, as illustrated in Figure 9, from which the physical meaning of Equation (1) can be understood more clearly. Similarly, for simplicity and essential comparison, the influences of different velocities, axial pressures, temperatures, and breakaway frictions on the friction damping behavior of FPBs [5,39] were neglected. In addition, the external disturbance and dynamic responses in only one horizontal principle direction were considered herein. 


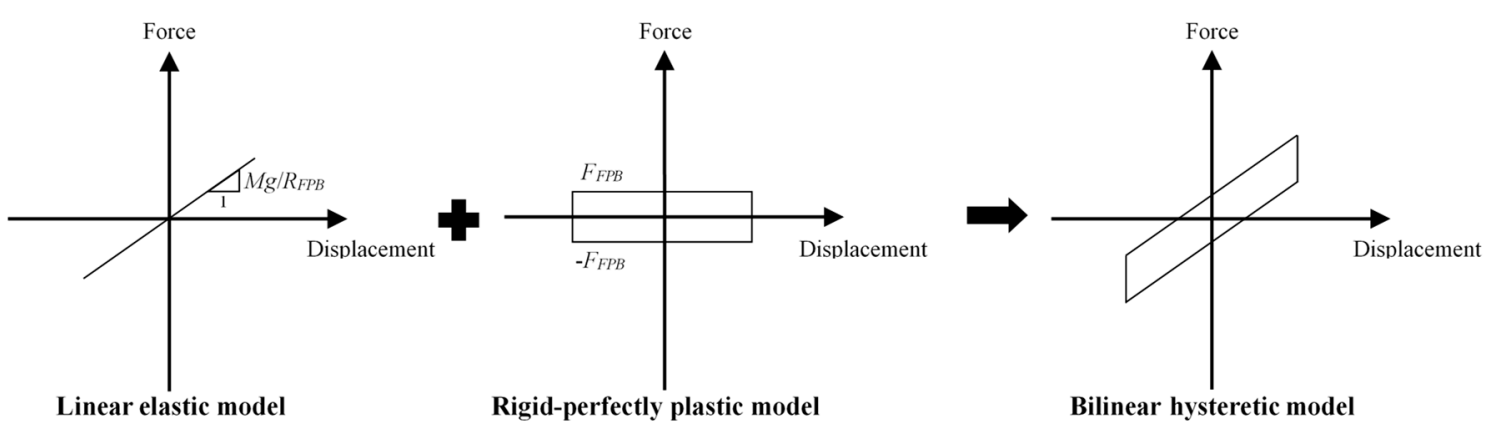

Figure 9. Idealized composition of analytical models for FPBs.

\subsection{FPB Models}

To quantitatively and objectively discuss the potential advantages of FPBs and SRBs in diverse aspects, the seismic responses of SRB-3 and SRB-6, as detailed in Section 3.2, were referred by the design criteria for the FPB models first and then were compared with those of the FPB models designed. Ground motions of Groups 2 and 3, as detailed in Section 2 and listed in Table 1, were also employed herein. More precisely, first, the average of maximum horizontal displacement responses of each SRB model, respectively, subjected to ground motions of Groups 2 and 3 was considered as the design displacement $\left(D_{D}\right)_{i}(i=2$ and 3) for the FPB model, as given in Equation (8). At the design displacement, the FPB model had the same horizontal acceleration response as the SRB model, i.e., 0.08.g. Through referring to SRB-3 subjected to ground motions of Group 2, the friction damping force designed for the FPB model (denoted as FPB-3-2M hereafter) was the same as that for SRB-3, as illustrated in Figure 10a. In other words, at any horizontal displacement, FPB-3-2M and SRB-3 had the same energy dissipation area caused by the friction damping force. Similarly, through referring to SRB-3 subjected to ground motions of Group 3, SRB-6 subjected to ground motions of Group 2, and SRB-6 subjected to ground motions of Group 3, the friction damping forces designed for the FPB models (correspondingly denoted as FPB-3-3M, FPB-6-2M, and FPB-6-3M hereafter) were identical to those for SRB-3, SRB-6, and SRB-6, respectively, as illustrated in Figure 10. The curved sliding surfaces designed for FPB-3-2M, FPB-3-3M, FPB-6-2M, and FPB-6-3M, as well as the sloped rolling surfaces designed for SRB-3 and SRB-6, are conceptually illustrated in Figure 11 for a better comparison of their different geometrical dimensions. Based on the design criteria aforementioned, the design parameters of FPB-3-2M, FPB-3-3M, FPB-6-2M, and FPB-6-3M can be determined, as also listed in Table 2. Note: based on the design criteria, when subjected to ground motions of Group 3, i.e., near-fault pulse-like ground motions, the FPB models were designed with a considerable curvature radius, which might not often be seen for practical application when simply considering far-field ground motions.

$$
\left(D_{D}\right)_{i}=\frac{\sum_{j=1}^{n} D_{i, j}^{\max }}{n}, \quad i=2 \text { and } 3,
$$

where $i$ represents the ground motions of Group $i(i=2$ and 3$) ; j$ represents the $j$ th ground motion of Group 2 or 3; $n$ represents the number of ground motions of Group 2 or 3 (for Groups 2 and 3,n= 25 and 41 , respectively); $D_{i, j}^{\max }$ is the maximum horizontal displacement response of SRB- 3 or SRB- 6 subjected the $j$ th ground motion of Group $i$. 


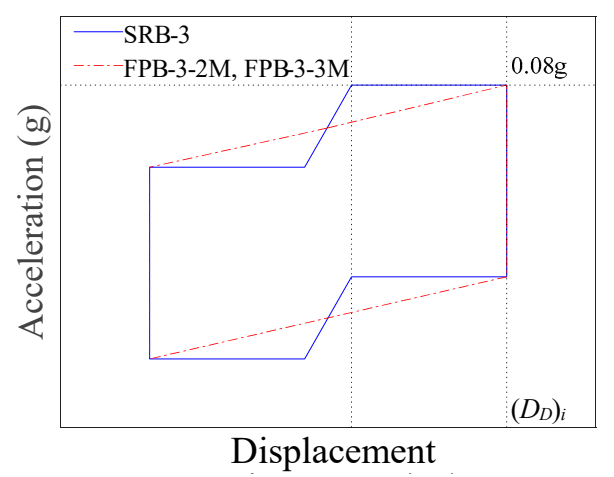

(a) SRB-3, FPB-3-2M, and FPB-3-3M.

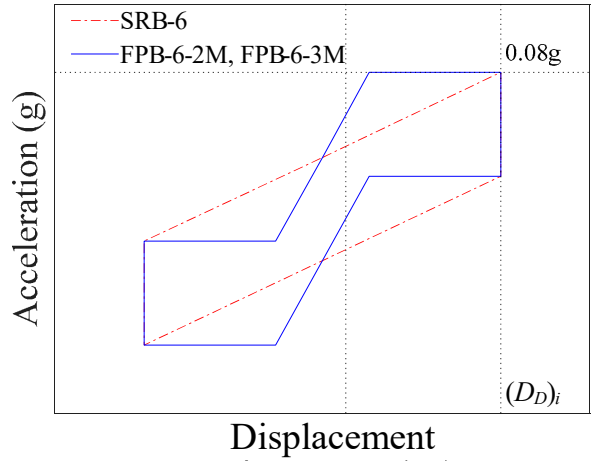

(b) SRB-6, FPB-6-2M, and FPB-6-3M.

Figure 10. Illustrations of design criteria for FPB models.

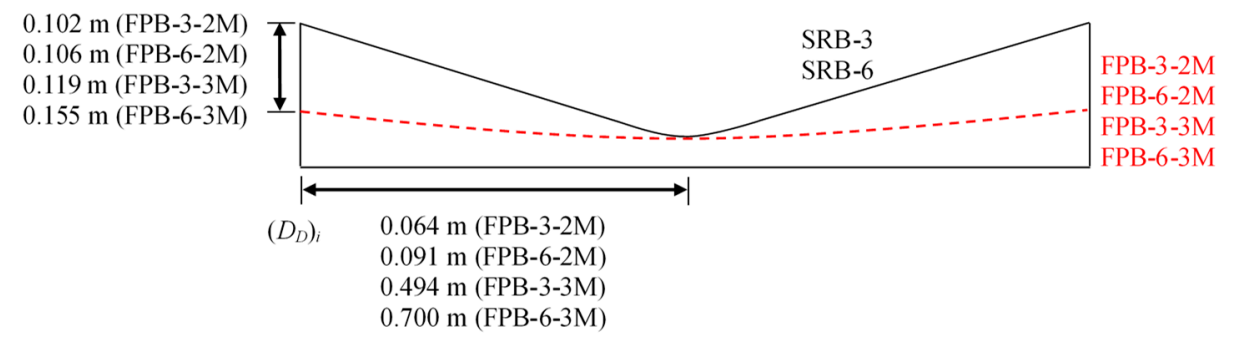

Figure 11. Illustrations of curved sliding and sloped rolling surfaces correspondingly designed for FPB and SRB models.

The design criteria for the FPB models aforementioned were based on the mean response subjected to ground motions of Group 2 or 3, which is called Benchmark I hereafter. For more comprehensive comparison and considering the effects caused by diverse ground motions, different FPB models designed based on the maximum horizontal displacement response of each SRB model subjected to each ground motion, i.e., $\left(D_{D}\right)_{i, j}(i=2$ and $3 ; j=1 \sim n)$, as calculated by Equation (9), were also considered herein, which is called Benchmark II hereafter. In short, Benchmark II is basically and conceptually the same as Benchmark I, except that the maximum horizontal displacement response of each SRB model subjected to each ground motion was considered, in lieu of the average of maximum horizontal displacement responses of each SRB model subjected to ground motions of Group 2 or 3. Thus, a total of 132 FPB models based on Benchmark II were designed accordingly (considering two SRB models and 66 sets of ground motions). Among these, the FPB models designed based on the responses of SRB-3 and SRB-6 subjected to any ground motion of Group 2 were denoted as generalized forms of FPB-3-2 and FPB-6-2, respectively, and those subjected to any ground motion of Group 3 were denoted as generalized forms of FPB-3-3 and FPB-6-3, respectively.

$$
\left(D_{D}\right)_{i, j}=D_{i, j}^{\max }, \quad i=2 \text { and } 3 ; j=1 \sim n
$$

\subsection{Comparison Results and Discussions}

The protected object above the FPB models and the associated conditions were the same as those introduced in Section 3.3. For numerically simulating the FPB models, at each time step of ground motions of Groups 2 and 3, the Newmark- $\beta$ method with linear acceleration was used for solving Equation (1). The same method as that described in Section 3.3 but a different formula, as given in Equation (10), was employed herein to consider the sticking phase [40] for the FPB models.

$$
F_{F P B}^{C}=\left|M \ddot{u}_{g}+\frac{M g}{R_{F P B}} u\right|,
$$


The maximum horizontal acceleration and displacement responses, as well as the residual displacement responses of SRB-3, FPB-3-2M, FPB-3-3M, FPB-3-2, FPB-3-3, SRB-6, FPB-6-2M, FPB-6-3M, FPB-6-2, and FPB-6-3 subjected to ground motions of Groups 2 and 3, are presented in Figures 12-14, respectively. For better comparison, the response ratios of FPB-3-2M to SRB-3, FPB-3-3M to SRB-3, FPB-3-2 to SRB-3, FPB-3-3 to SRB-3, FPB-6-2M to SRB-6, FPB-6-3M to SRB-6, FPB-6-2 to SRB-6, and FPB-6-3 to SRB- 6 are also presented. The numbers indicated in these figures represent the amounts of ground motions under which the control performances of the FPB models were better than those of the corresponding SRB models. In addition to mean responses, the 25th and 75th percentile responses are also provided for further statistical comparison. The numerical results of SRB-3 and SRB- 6 at the arc rolling stage, i.e., the maximum horizontal acceleration responses less than $0.08 \cdot g$ shown in Figure 12, are covered in the figures and the following discussions. As observed from Figure 13, evidently, since all the maximum horizontal displacement responses were larger than zero, the situation that the SRB or FPB models were not activated (i.e., were not functional) under the ground motions considered did not occur. Figures 15 and 16 present the displacement and acceleration response histories as well as the hysteresis loops of SRB-3, FPB-3-2, SRB-6, and FPB-6-2 under 1999 Taiwan Chi-Chi, TCU074 (EW) (one of the ground motions of Group 2) and those of SRB-3, FPB-3-3, SRB-6, and FPB-6-3 under 1999 Taiwan Chi-Chi, TCU052 (EW) (one of the ground motions of Group 3), respectively. Note again that this numerical study aimed to discuss the potential merits of FPBs and SRBs quantitatively based on the design criteria described in Section 4.2, rather than to design practically acceptable horizontal isolation displacement as small (or satisfactory) as possible for FPBs and SRBs against the ground motion considered.

As observed from Figures 12, 15 and 16, the distribution of maximum horizontal acceleration responses of the FPB models was much more scattered than that of the SRB models, even considering the responses of the SRB models at the arc rolling stage (only SRB-6 under one far-field ground motion). It is mainly because of the unique feature of SRBs-constant acceleration control. Under 15 (13) and 20 (21) sets (i.e., the majority) of far-field ground motions, FPB-3-2M (FPB-3-2) and FPB-6-2M (FPB-6-2) had better horizontal acceleration control performances than SRB-3 and SRB-6, respectively, in particular, the latter. Under 28 (28) sets and 37 (36) sets (i.e., the majority) of pulse-like near-fault ground motions, FPB-3-3M (FPB-3-3) and FPB-6-3M (FPB-6-3) had better horizontal acceleration control performances than SRB-3 and SRB-6, respectively, in particular, the latter. Without considering the extremes, the response ratios on average, regardless of being subjected to far-field or pulse-like near-fault ground motions, were less than unity. To sum up, under the ground motions considered, if simply observing the amount or the average of response ratios, the FPB models might potentially have an advantage over the SRB models in terms of horizontal acceleration control. In addition, by comparing FPB-6-2M (FPB-6-2) with FPB-3-2M (FPB-3-2) and FPB-6-3M (FPB-6-3) with FPB-3-3M (FPB-3-3) in terms of maximum horizontal acceleration, with the same acceleration control performance, the FPB models designed with a larger design displacement, a smaller curvature radius, and a smaller damping force might potentially have a better horizontal acceleration control performance than those designed with a smaller design displacement, a larger curvature radius, and a larger damping force. 

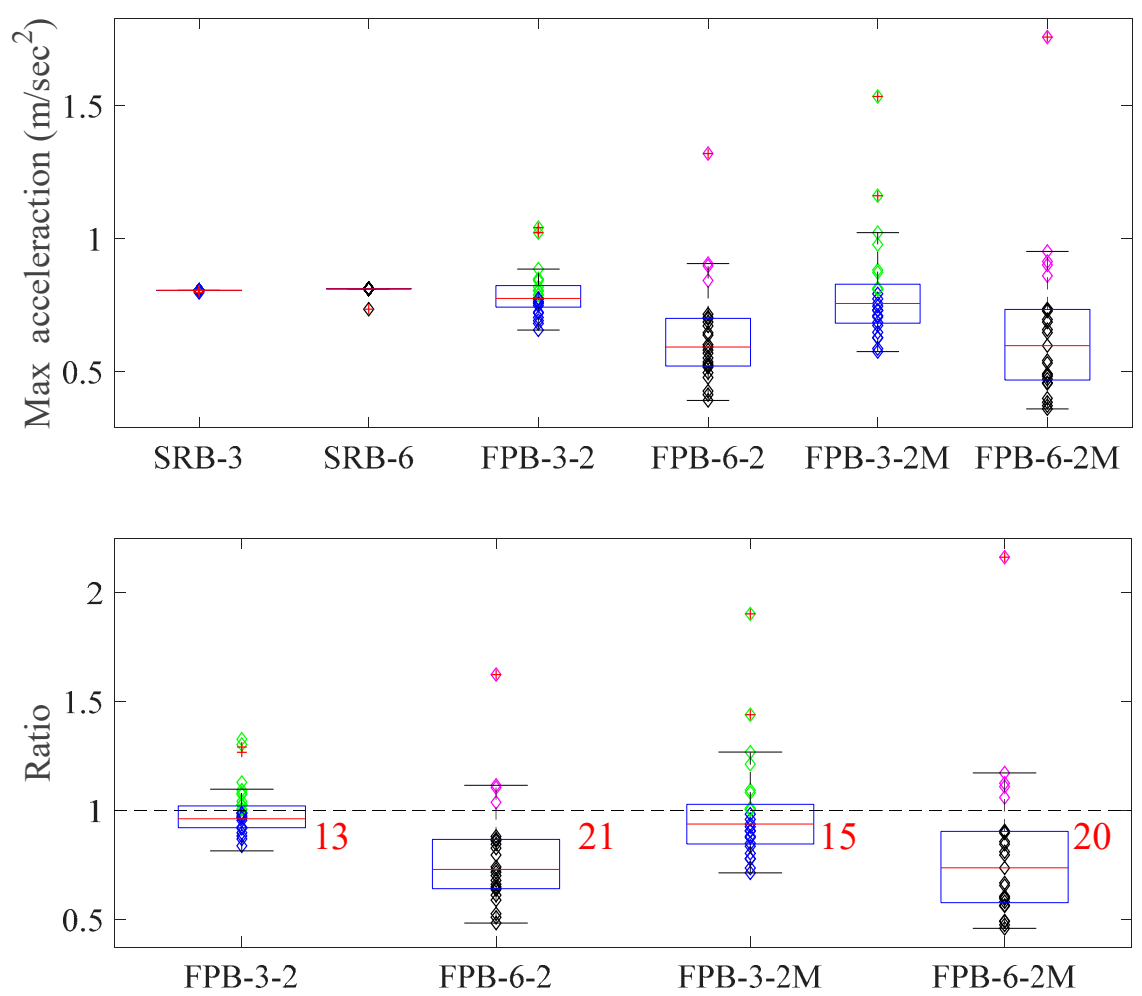

(a) Group 2 (25 sets of far-field ground motions).
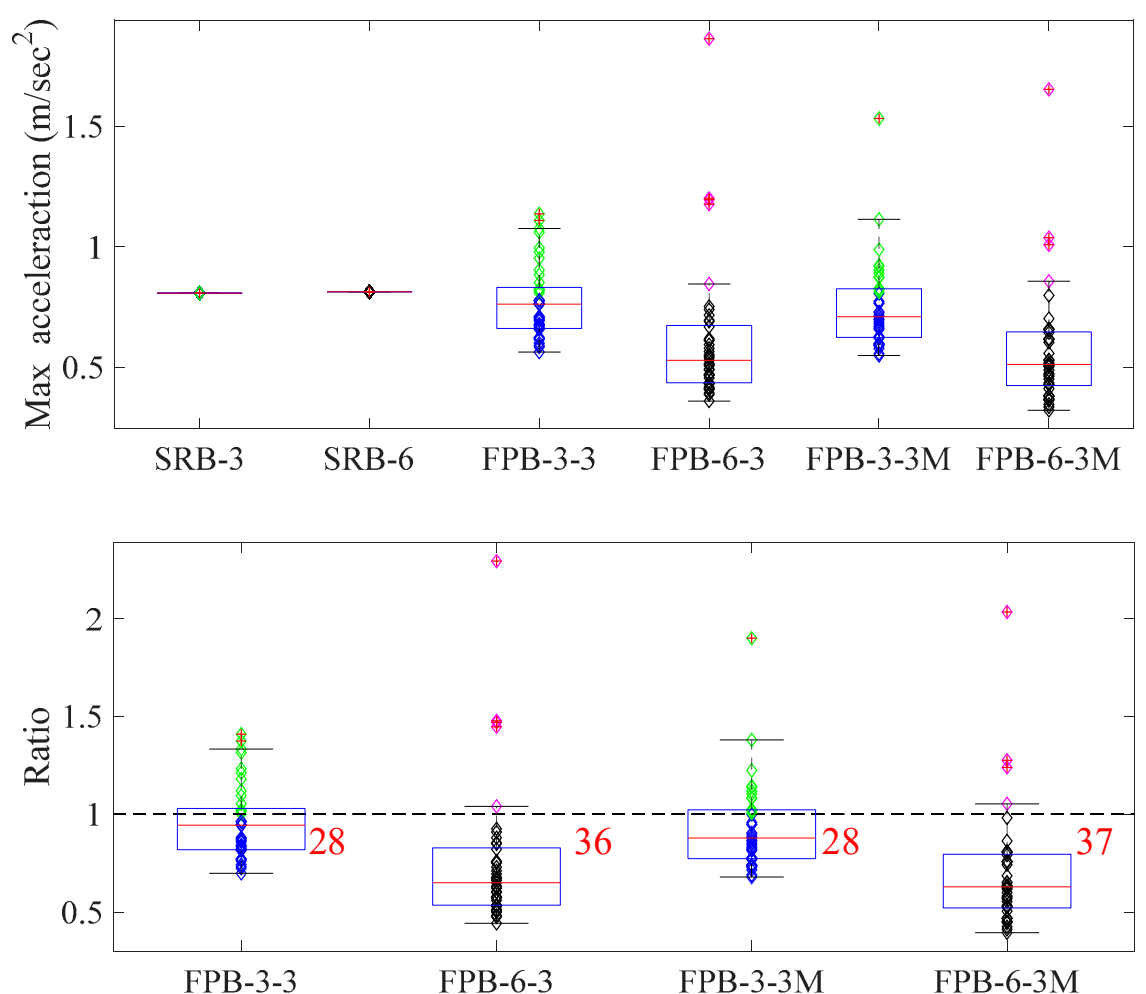

(b) Group 3 (41 sets of pulse-like near-fault ground motions).

Figure 12. Comparisons of maximum horizontal acceleration responses of SRBs and FPBs subjected to different ground motions. 

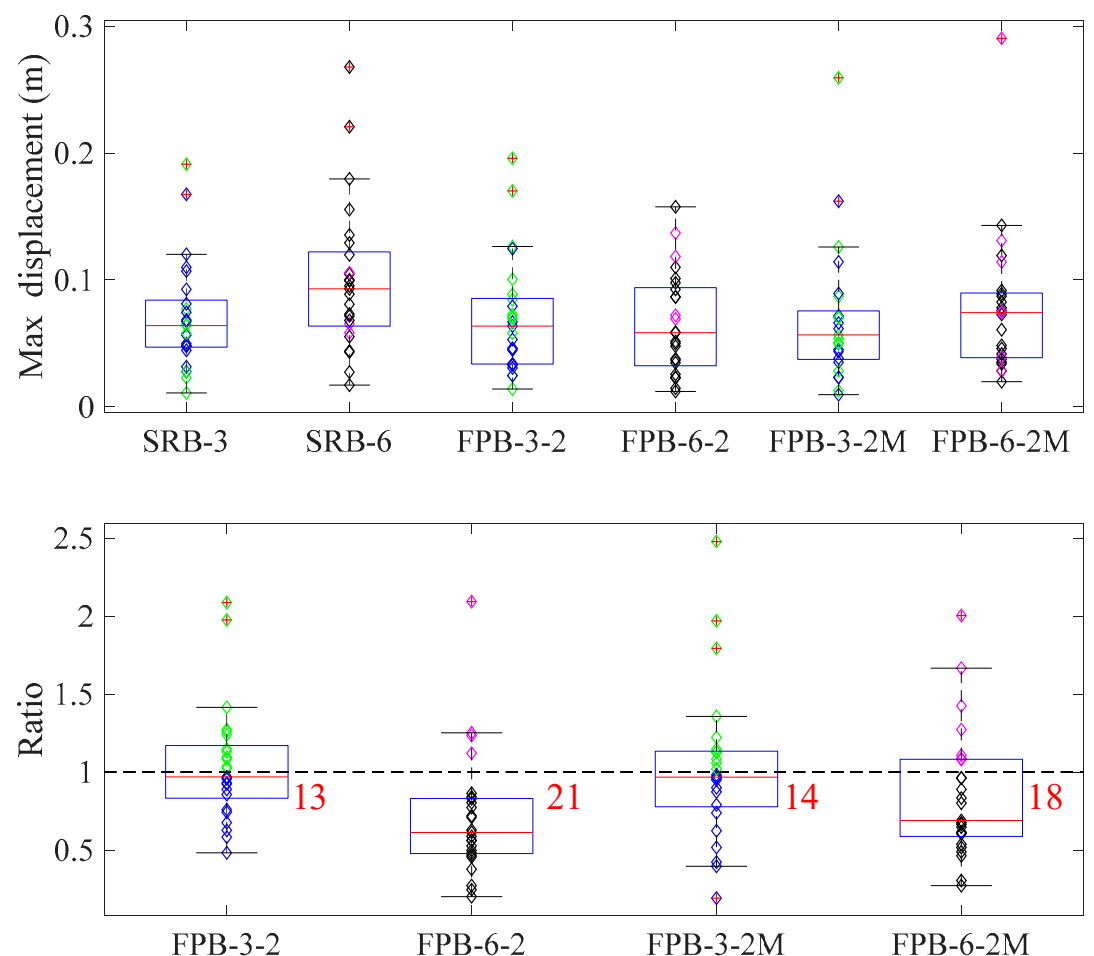

(a) Group 2 (25 sets of far-field ground motions).
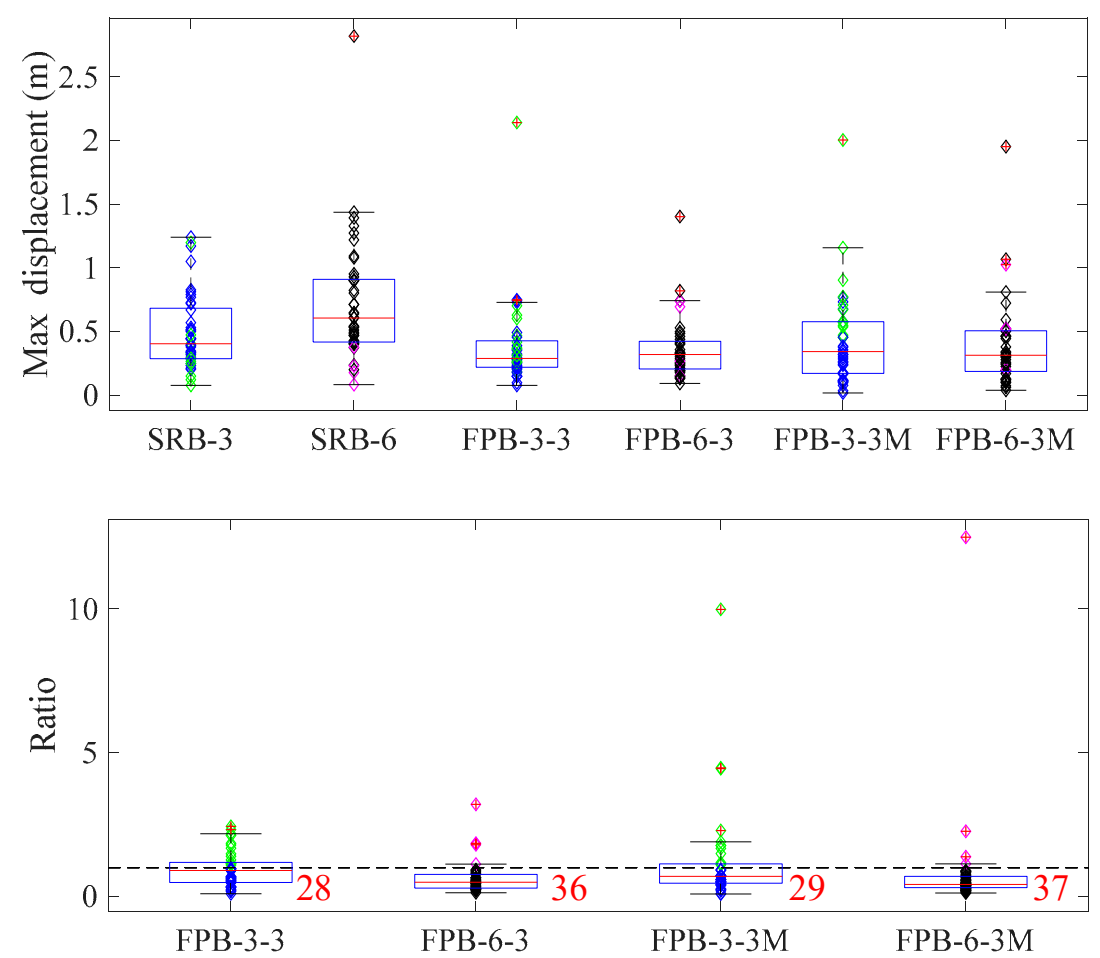

(b) Group 3 (41 sets of pulse-like near-fault ground motions).

Figure 13. Comparisons of maximum horizontal displacement responses of SRBs and FPBs subjected to different ground motions. 

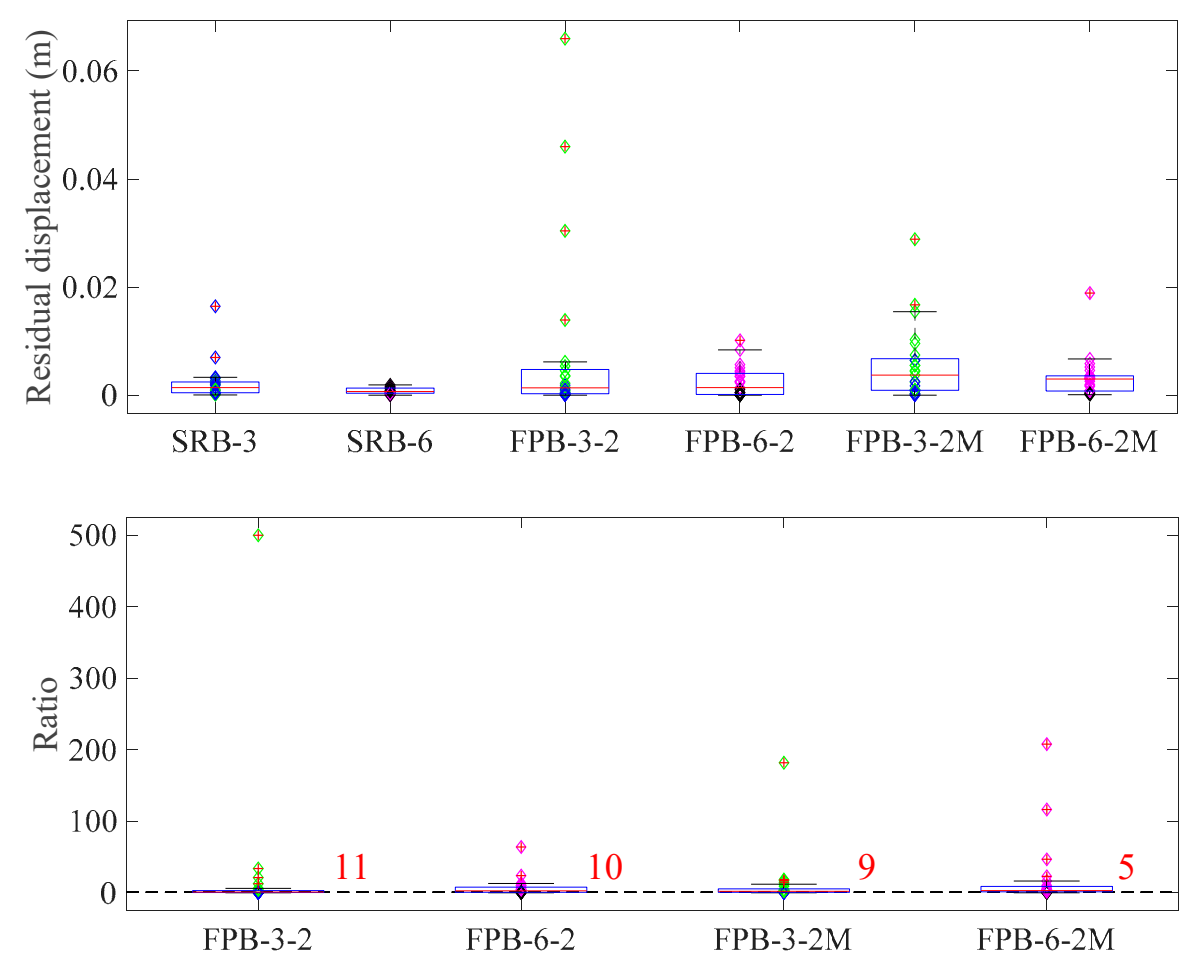

(a) Group 2 (25 sets of far-field ground motions).
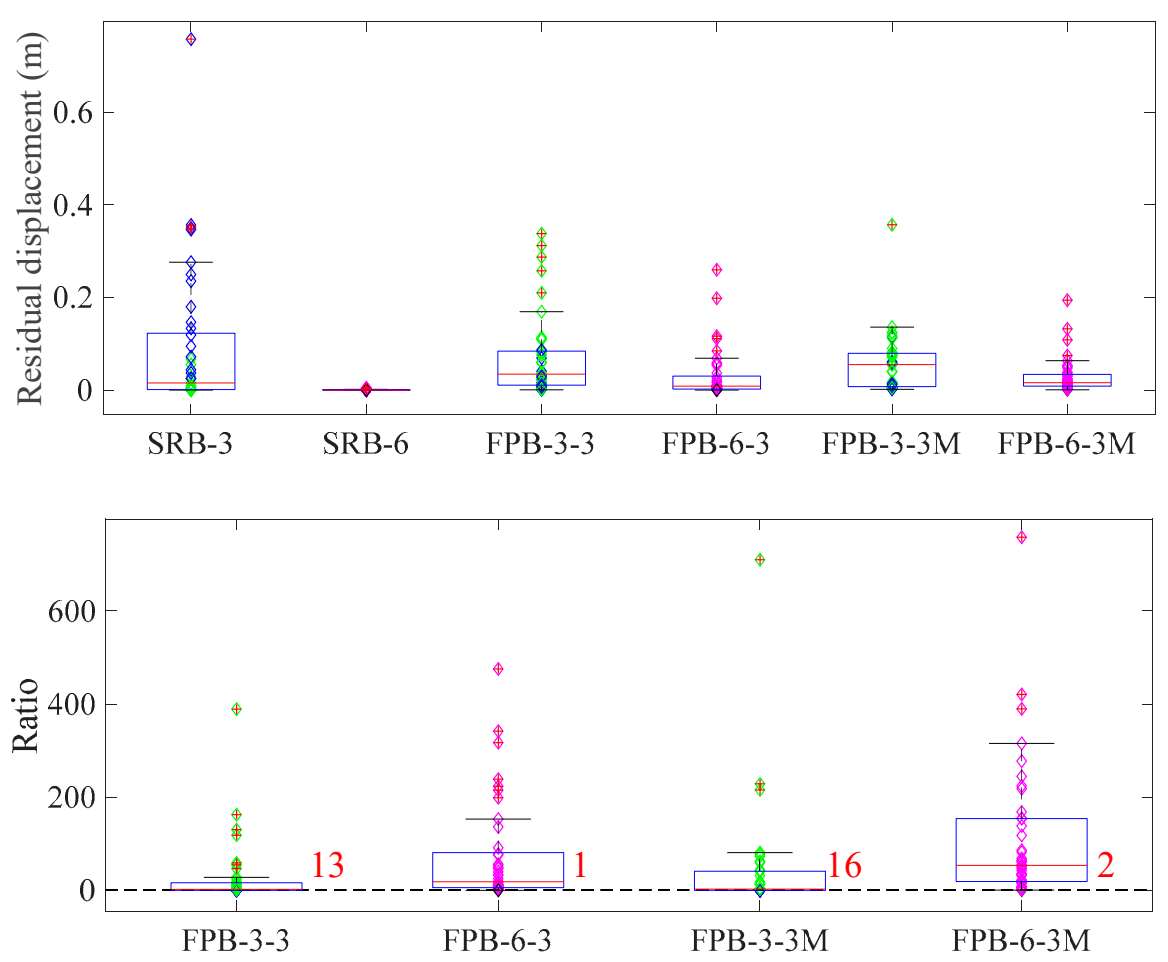

(b) Group 3 (41 sets of pulse-like near-fault ground motions).

Figure 14. Comparisons of residual displacement responses of SRBs and FPBs subjected to different ground motions. 

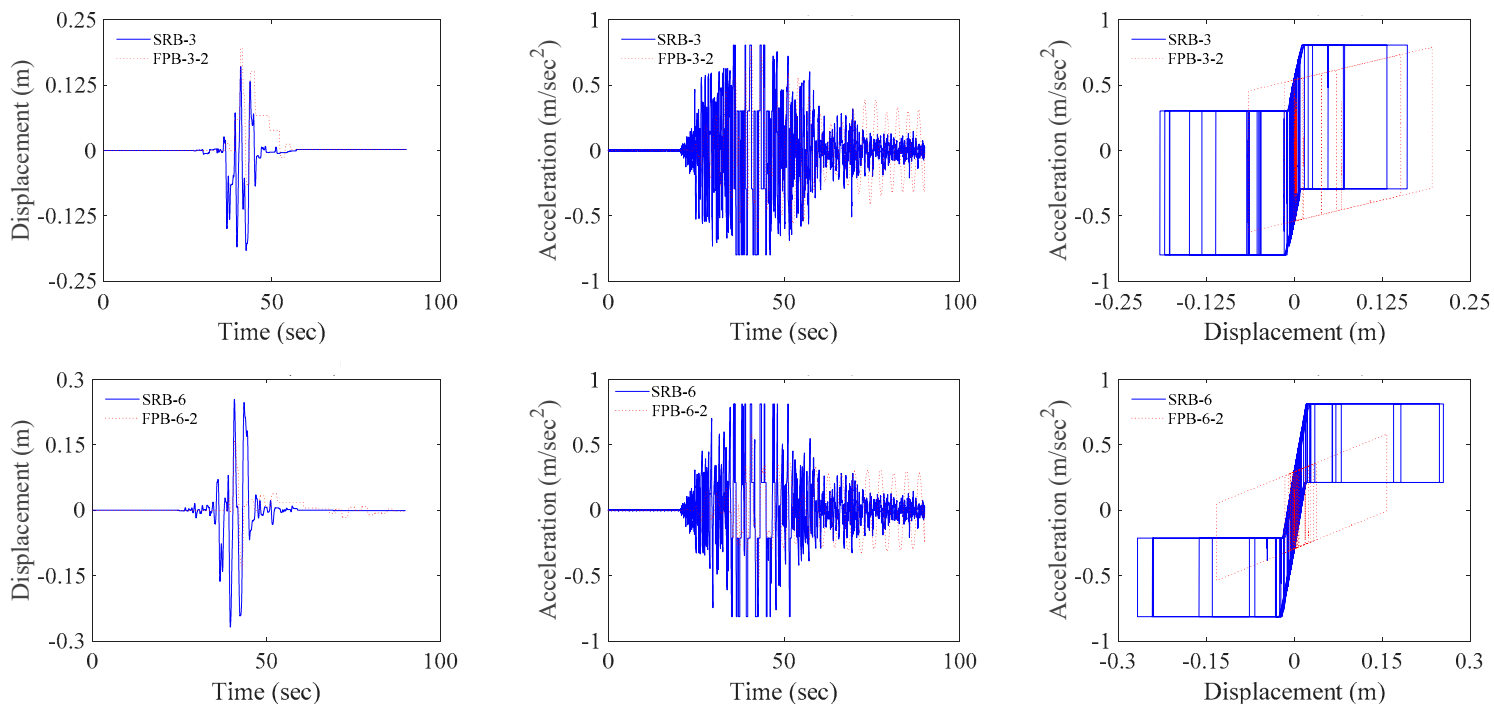

(a) Displacement response histories.

(b) Acceleration response histories.

(c) Hysteresis loops.

Figure 15. Numerical results of SRB-3, FPB-3-2, SRB-6, and FPB-6-2 under 1999 Taiwan Chi-Chi, TCU074 (EW) (Group 2).
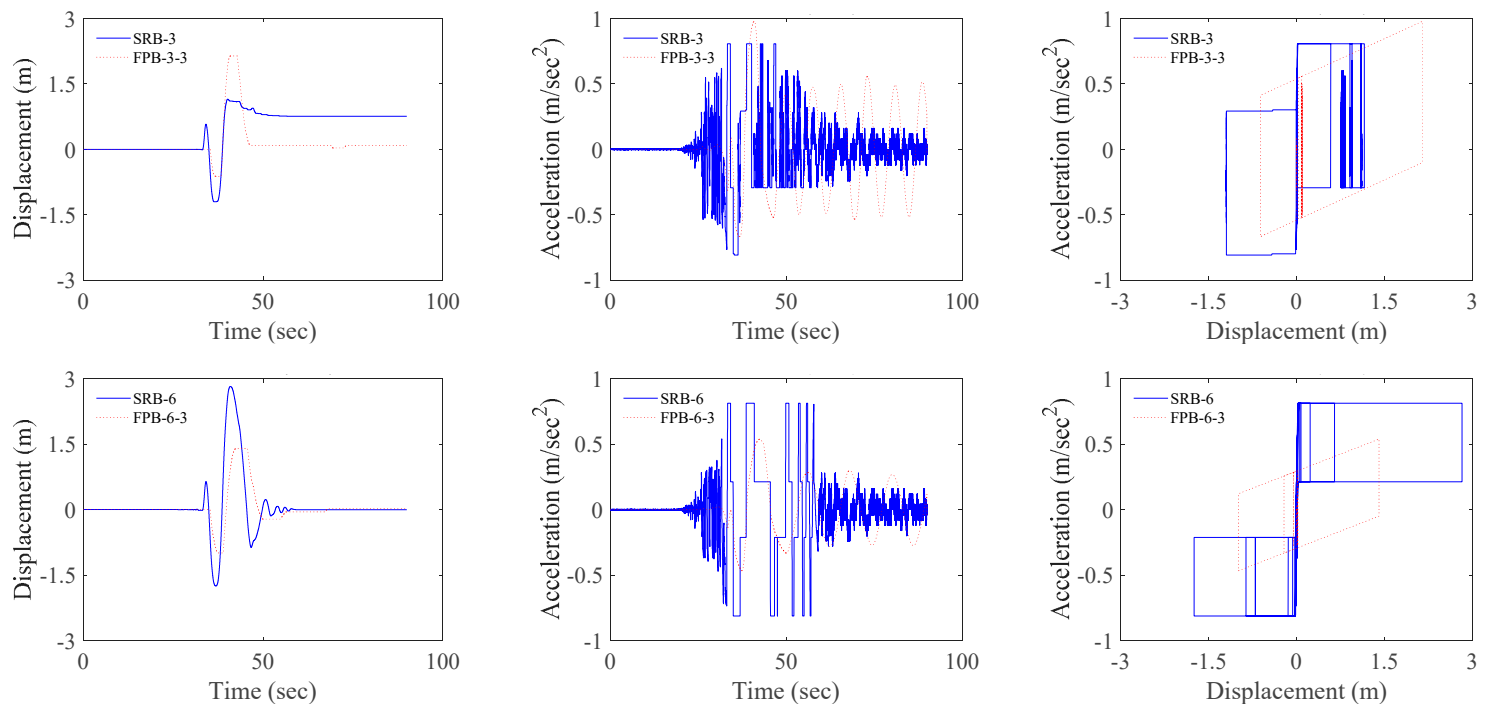

(a) Displacement response histories.

(b) Acceleration response histories.

(c) Hysteresis loops.

Figure 16. Numerical results of SRB-3, FPB-3-3, SRB-6, and FPB-6-3 under 1999 Taiwan Chi-Chi, TCU052 (EW) (Group 3).

As observed from Figures 13, 15 and 16, under 14 (13) and 18 (21) sets (i.e., the majority) of far-field ground motions, FPB-3-2M (FPB-3-2) and FPB-6-2M (FPB-6-2) had smaller horizontal isolation displacement than SRB-3 and SRB-6, respectively, in particular, the latter. Under 29 (28) sets and 37 (36) sets (i.e., the majority) of pulse-like near-fault ground motions, FPB-3-3M (FPB-3-3) and FPB-6-3M (FPB-6-3) had smaller horizontal isolation displacement than SRB-3 and SRB-6, respectively, in particular, the latter. Note that the amounts for FPB-3-2 and FPB-6-2 shown in Figure 13 are the same as those shown in Figure 12. It is reasonable because FPB-3-2 and FPB-6-2 were designed based on the maximum horizontal displacement responses of SRB-3 and SRB-6 subjected to each ground motion, i.e., Benchmark II. If FPB-3-2 (FPB-6-2) had a larger horizontal acceleration response than SRB-3 (or SRB-6) 
under a given ground motion, it also meant that FPB-3-2 (FPB-6-2) had a larger horizontal displacement response than SRB-3 (SRB-6), and vice versa. Without considering the extremes, the response ratios on average, regardless of being subjected to far-field or pulse-like near-fault ground motions, were less than unity. To sum up, under the ground motions considered, if simply observing the amount or the average of the response ratios, the FPB models might be potentially more effective than the SRB models in reducing maximum horizontal displacement responses. By comparing FPB-6-2M (FPB-6-2) with FPB-3-2M (FPB-3-2) and FPB-6-3M (FPB-6-3) with FPB-3-3M (FPB-3-3) in terms of maximum horizontal displacement, with the same acceleration control performance, the horizontal displacement control performances of the different FPB models seemed to be not very different.

As observed from Figures 14-16, only under 9 (11) and 5 (10) sets (i.e., the minority) of far-field ground motions, FPB-3-2M (FPB-3-2) and FPB-6-2M (FPB-6-2) had superior re-centering performances to SRB-3 and SRB-6, respectively. Only under 16 (13) sets (i.e., the minority) and 2 (1) sets (i.e., the minority and even almost none) of pulse-like near-fault ground motions, FPB-3-3M (FPB-3-3) and FPB-6-3M (FPB-6-3) had superior re-centering performances to SRB-3 and SRB-6, respectively. Without considering the extremes, the response ratios on average, regardless of being subjected to far-field or pulse-like near-fault ground motions, were larger than unity. To sum up, under the ground motions considered, if simply observing the amount or the average of the response ratios, the SRB models, SRB-6 (i.e., the design with a larger sloping angle and a smaller damping force) in particular, might be potentially more effective than the FPB models in controlling residual displacement responses. It is because of its larger sloping angle (or higher potential energy, as explained in Section 3.3) at the design displacement shown in Figure 11. Another reason might be its smaller static residual displacement to which the theoretical or statistical permanent residual displacement is proportional [24,36]. However, it is emphasized again that with the same horizontal acceleration control performance, as clearly observed from Figure 13, SRB-6 almost had the largest, and even practically unacceptable, horizontal isolation displacement among all the SRB and FPB models, regardless of being subjected to far-field or pulse-like near-fault ground motions. In addition, by comparing FPB-6-2M (FPB-6-2) with FPB-3-2M (FPB-3-2) and FPB-6-3M (FPB-6-3) with FPB-3-3M (FPB-3-3) in terms of residual displacement, with the same acceleration control performance, the FPB models designed with a larger design displacement, a smaller curvature radius, and a smaller damping force might potentially have a better self-centering performance than those designed with a smaller design displacement, a larger curvature radius, and a larger damping force.

\section{Conclusions}

Based on the well-developed simplified analytical models for FPBs and SRBs, this study attempts to numerically discuss their passive control performances, in terms of horizontal transmitted acceleration, isolation displacement, and post-earthquake residual displacement, which have been rarely studied before. To have objective comparison results, the first criterion adopted in this study for designing the FPB model was that at the horizontal isolation displacement identical to the maximum horizontal displacement response of the SRB model under a given seismic demand, the two different models have the same horizontal acceleration control performance. The second criterion was that an horizontal isolation displacement, the two different models have the same energy dissipation capability. Some conclusions obtained from the numerical results and comparisons are made as follows.

1. This study briefly introduced and compared the features, equations of motion, and simplified analytical models of FPBs and SRBs. A large number of local and global ground motion records, including the so-called far-field and pulse-like near-fault ones, were adopted as the horizontal acceleration inputs for the numerical analysis on different SRB and FPB models designed based on the criteria considered. It is emphasized again that the purpose of the diverse ground motions considered and the models designed in this study was to obtain wide-ranging seismic responses of the models, rather than to passively reduce their seismic responses as small (or satisfactory) as possible or to propose optimum design approaches for FPBs and SRBs. 
2. Based on retaining the same horizontal acceleration control performance, the numerical results of four SRB models designed with different sloping angles and damping forces under the ground motions considered indicated that suppressing horizontal isolation displacement and reducing residual displacement were always two antithetic functions for SRBs simply designed with a constant sloping angle and damping force. In other words, under the same excitation, it is evident that the larger the damping force or, the smaller the sloping angle, the smaller the horizontal isolation displacement presented, but the more significant the residual displacement obtained.

3. With the same horizontal acceleration control performance, the numerical results of hundreds of FPB models under the ground motions considered showed that the FPB models designed with a larger design displacement, a smaller curvature radius, and a smaller damping force might potentially have a better horizontal acceleration control and self-centering performances than those designed with a smaller design displacement, a larger curvature radius, and a larger damping force.

4. On the premise of retaining the same horizontal acceleration control performance, the numerical results of two SRB models and hundreds of FPB models under the ground motions considered indicated that although the SRB models possess a unique feature-constant acceleration responses-the FPB models, on average, might potentially have a slight advantage over the SRB models in terms of horizontal acceleration control. Besides, the FPB models might also be potentially more effective than the SRB models in suppressing horizontal isolation displacement. As for the re-centering capability, the SRB model designed with a larger sloping angle is potentially better than that designed with a smaller sloping angle as well as the FPB models.

In this research, the numerical study only considered two SRB models as the benchmarks for comparison with the FPB models might not be generalized enough. Nevertheless, some important quantitative results consistent with the theoretical bases and features of FPBs and SRBs, can still be obtained. These results are valuable for the whole picture of comparison of the two kinds of isolation bearings (i.e., FPBs and SRBs) or even the two types of hysteretic behavior (bilinear and twin-flag hysteretic behavior), as detailed in the fourth conclusion. In the future, SRB models designed with more different acceleration performance goals as well as designed with more diverse combinations of constant sloping angles and damping forces might be further considered as benchmarks for a more comprehensive comparison. In addition, further comparison of FPBs designed with different curvature radii and friction coefficients and SRBs designed with variable sloping angles and damping forces might also be made.

Author Contributions: Conceptualization, resources, methodology, writing-original draft preparation, supervision, project administration, and funding acquisition, S.-J.W.; software, validation, formal analysis, investigation, and data curation, Y.-L.S.; methodology, investigation, and writing-review and editing, C.-Y.Y., W.-C.L., and C.-H.Y. All authors have read and agreed to the published version of the manuscript.

Funding: This research was funded by the Ministry of Science and Technology (MOST), Taiwan, grant number MOST 105-2221-E-011-169-MY2. The APC was funded by the Ministry of Science and Technology (MOST), Taiwan.

Acknowledgments: The study was financially aided by the Ministry of Science and Technology (MOST), Taiwan, grant number MOST 105-2221-E-011-169-MY2. The support is greatly acknowledged.

Conflicts of Interest: The authors declare no conflict of interest.

\section{References}

1. Calvi, P.M.; Calvi, G.M. Historical development of friction-based seismic isolation systems. Soil Dyn. Earthq. Eng. 2018, 106, 14-30. [CrossRef]

2. Harvey, P.S., Jr.; Kelly, K.C. A review of rolling-type seismic isolation: Historical development and future directions. Eng. Struct. 2016, 125, 521-531. [CrossRef]

3. Zayas, V.A.; Low, S.S.; Mahin, S.A. A simple pendulum technique for achieving seismic isolation. Earthq. Spectra 1990, 6, 317-333. [CrossRef] 
4. Mokha, A.; Constantinou, M.C.; Reinhorn, A.M. Teflon bearings in base isolation. I: Testing. J. Struct. Eng. ASCE 1990, 116, 438-454. [CrossRef]

5. Constantinou, M.; Mokha, A.; Reinhorn, A.M. Teflon bearings in base isolation. II: Modeling. J. Struct. Eng. ASCE 1990, 116, 455-474. [CrossRef]

6. Mokha, A.; Constantinou, M.C.; Reinhorn, A.M.; Zayas, V.A. Experimental study of friction-pendulum isolation system. J. Struct. Eng. ASCE 1991, 117, 1201-1217. [CrossRef]

7. Deringöl, A.H.; Güneyisi, E.M. Effect of friction pendulum bearing properties on behaviour of buildings subjected to seismic loads. Soil Dyn. Earthq. Eng. 2019, 125, 105746. [CrossRef]

8. Fenz, D.M.; Constantinou, M.C. Behaviour of the double concave friction pendulum bearing. Earthq. Eng. Struct. Dyn. 2006, 35, 1403-1424. [CrossRef]

9. Fenz, D.M.; Constantinou, M.C. Modeling triple friction pendulum bearings for response-history analysis. Earthq. Spectra 2008, 24, 1011-1028. [CrossRef]

10. Kim, Y.S.; Yu, C.B. Seismic response characteristics of bridges using double concave friction pendulum bearings with tri-linear behavior. Eng. Struct. 2007, 29, 3082-3093. [CrossRef]

11. Calvi, P.M.; Moratti, M.; Calvi, G.M. Seismic isolation devices based on sliding between surfaces with variable friction coefficient. Earthq. Spectra 2016, 32, 2291-2315. [CrossRef]

12. Panchal, V.R.; Jangid, R.S. Variable friction pendulum system for near-fault ground motions. Struct. Control Health Monit. 2008, 15, 568-584. [CrossRef]

13. Bao, Y.; Becker, T. Three-dimensional double friction pendulum bearing model including uplift and impact behavior: Formulation and numerical example. Eng. Struct. 2019, 199, 109579. [CrossRef]

14. Lee, D.; Constantinou, M.C. Quintuple friction pendulum isolator: Behavior, modeling, and validation. Earthq. Spectra 2019, 32, 1607-1626. [CrossRef]

15. Lu, L.Y.; Lee, T.Y.; Juang, S.Y.; Yeh, S.W. Polynomial friction pendulum isolators (PFPIs) for building floor isolation: An experimental and theoretical study. Eng. Struct. 2013, 56, 970-982. [CrossRef]

16. Saha, A.; Saha, P.; Patro, S.K. Polynomial friction pendulum isolators (PFPIs) for seismic performance control of benchmark highway bridge. Earthq. Eng. Eng. Vib. 2017, 16, 827-840. [CrossRef]

17. Panchal, V.R.; Jangid, R.S.; Soni, D.P.; Mistry, B.B. Response of the double variable frequency pendulum isolator under triaxial ground excitations. J. Earthq. Eng. 2010, 14, 527-558. [CrossRef]

18. Becker, T.C.; Mahin, S.A. Experimental and analytical study of the bi-directional behavior of the triple friction pendulum isolator. Earthq. Eng. Struct. Dyn. 2012, 41, 355-373. [CrossRef]

19. Sah, V.M.; Soni, D.P. Response of the double concave friction pendulum system under triaxial ground excitations. Procedia Eng. 2017, 173, 1870-1877. [CrossRef]

20. Furinghetti, M.; Pavese, A.; Quaglini, V.; Dubini, P. Experimental investigation of the cyclic response of double curved surface sliders subjected to radial and bidirectional sliding motions. Soil Dyn. Earthq. Eng. 2019, 117, 190-202. [CrossRef]

21. Loghman, V.; Khoshnoudian, F.; Banazadeh, M. Effect of vertical component of earthquake on seismic responses of triple concave friction pendulum base-isolated structures. J. Vib. Control 2015, 21, 2099-2113. [CrossRef]

22. Faramarz, K.; Montazar, R. Seismic response of double concave friction pendulum base-isolated structures considering vertical component of earthquake. Adv. Struct. Eng. 2010, 13, 1-14. [CrossRef]

23. Jangid, R.S. Optimum friction pendulum system for near-fault motions. Eng. Struct. 2005, 27, 349-359. [CrossRef]

24. Katsaras, C.P.; Panagiotakos, T.B.; Kolias, B. Restoring capability of bilinear hysteretic seismic isolation systems. Earthq. Eng. Struct. Dyn. 2008, 37, 557-575. [CrossRef]

25. Cardone, D.; Gesualdi, G.; Brancato, P. Restoring capability of friction pendulum seismic isolation systems. Bull. Earthq. Eng. 2015, 13, 2449-2480. [CrossRef]

26. Ponzo, F.C.; Cesare, A.D.; Leccese, G.; Nigro, D. Shake table testing on restoring capability of double concave friction pendulum seismic isolation systems. Earthq. Eng. Struct. Dyn. 2017, 46, 2337-2353. [CrossRef]

27. Forcellini, D. Cost assessment of isolation technique applied to a benchmark bridge configuration with soil structure interaction. Bull. Earthq. Eng. 2017, 15, 51-69. [CrossRef]

28. Kasalanati, A.; Reinhorn, A.M.; Constantinou, M.C.; Sanders, D. Experimental study of ball-in-cone isolation system. In Proceedings of the ASCE Structures Congress XV, Portland, OR, USA, 13-16 April 1997. 
29. Tsai, M.H.; Wu, S.Y.; Chang, K.C.; Lee, G.C. Shaking table tests of a scaled bridge model with rolling type seismic isolation bearings. Eng. Struct. 2007, 29, 694-702. [CrossRef]

30. Vargas, R.; Bruneau, M. Experimental response of buildings designed with metallic Structural Fuses. II. J. Struct. Eng. ASCE 2009, 135, 394-403. [CrossRef]

31. Lee, G.C.; Ou, Y.C.; Niu, T.; Song, J.; Liang, Z. Characterization of a roller seismic isolation bearing with supplemental energy dissipation for highway bridges. J. Struct. Eng. ASCE 2010, 136, 502-510. [CrossRef]

32. Wang, S.J.; Hwang, J.S.; Chang, K.C.; Shiau, C.Y.; Lin, W.C.; Tsai, M.S.; Hong, J.X.; Yang, Y.H. Sloped multi-roller isolation devices for seismic protection of equipment and facilities. Earthq. Eng. Struct. Dyn. 2014, 43, 1443-1461. [CrossRef]

33. Wang, S.J.; Yu, C.H.; Lin, W.C.; Hwang, J.S.; Chang, K.C. A generalized analytical model for sloped rolling-type seismic isolators. Eng. Struct. 2017, 138, 434-446. [CrossRef]

34. Wang, S.J.; Yu, C.H.; Cho, C.Y.; Hwang, J.S. Effects of design and seismic parameters on horizontal displacement responses of sloped rolling-type seismic isolators. Struct. Control Health Monit. 2019, 26, e2342. [CrossRef]

35. Wang, S.J.; Sung, Y.L.; Hong, J.X. Sloped rolling-type bearings designed with linearly variable damping force. Earthq. Struct. 2020, 19, 129-144. [CrossRef]

36. Cardone, D. Re-centring capability of flag-shaped seismic isolation systems. Bull. Earthq. Eng. 2012, 10, 1267-1284. [CrossRef]

37. American Society of Civil Engineers (ASCE). Minimum Design Loads and Associated Criteria for Buildings and Other Structures, ASCE/SEI 7-16; American Society of Civil Engineers (ASCE): Reston, VA, USA, 2017.

38. Shahi, S.K.; Baker, J.W. An efficient algorithm to identify strong-velocity pulses in multicomponent ground motions. Bull. Seismol. Soc. Am. 2014, 104, 2456-2466. [CrossRef]

39. Kumar, M.; Whittaker, A.W.; Constantinou, M.C. Characterizing friction in sliding isolation bearings. Earthq. Eng. Struct. Dyn. 2015, 44, 1409-1425. [CrossRef]

40. He, W.L.; Agrawal, A.K.; Yang, J.N. Novel semiactive friction controller for linear structures against earthquakes. J. Struct. Eng. ASCE 2003, 129, 941-950. [CrossRef]

41. Hsu, T.Y.; Huang, C.H. A smart sloped rolling-type isolator using information from an onsite earthquake early-warning technique. In Proceedings of the Asian Pacific Congress on Computational Mechanics (APCOM), Taipei, Taiwan, 18-20 December 2019.

Publisher's Note: MDPI stays neutral with regard to jurisdictional claims in published maps and institutional affiliations.

(C) 2020 by the authors. Licensee MDPI, Basel, Switzerland. This article is an open access article distributed under the terms and conditions of the Creative Commons Attribution (CC BY) license (http://creativecommons.org/licenses/by/4.0/). 